\title{
Bioactivity of Biocellulose Based Film Incorporated with Cinnamomum cassia and Citrus maxima Oils
}

\author{
Yoice Srikandace $^{* 1}$, Ivana Giovani ${ }^{2}$, Nina Artanti ${ }^{3}$ \\ 1 Indonesian Institute of Sciences, Research Unit for Clean Technology, Bandung 40135 - Indonesia \\ 2 Surya University, Departement of Nutrition and Food Technology, Faculty of Life Sciences, Tangerang - Indonesia Country \\ 3 Indonesian Institute of Sciences, Research Center for Chemistry, Tangerang - Indonesia
}

Correspondence Author: Kwanho Kim, Dept. of Industrial Management and Engineering, Incheon National University, South Korea.

E-mail: yoice_srikandace@yahoo.co.id

Received date: 22 April 2019, Accepted date: 22 July 2019, Online date: 25 August 2019

Copyright: (c) 2019 Yoice Srikandace , Ivana Giovani, Nina Artanti .2019. This is an open-access article distributed under the terms of the Creative Commons Attribution License, which permits unrestricted use, distribution, and reproduction in any medium, provided the original author and source

Abstract
Background: The bacterial cellulose or biocellulose (BC) have been known as a natural, biodegradable and friendly
biopolymer. The bacterial cellulose based films have ability as carrier of bioactive compounds such as antioxidant and
antimicrobes in order to improve the value of BC film and characteristic properties. In present study, Cinnamomum
cassia and Citrus maxima essential oils (EOs) were added into BC slurry containing CMC and glycerol. BC slurry on
plates were dried to obtain films containing $1-3 \%$ EOs. Objective: All films were tested for their antioxidant activity
using DPPH method and antibacterial activity using dilution and spread methods. Result: All films containing
cinnamomum oil still showed antioxidant activity with inhibition of DPPH 85-91\% but only a film incorporated with
$3 \%$ C.maxima showed antioxidant activity (72.71\%). All films incorporated with $2-3 \%$ EOs also showed antibacterial
activity against the growth of Escherichia coli, Staphylococcus aureus, Salmonella thypii, Pseudomonas aeruginosa and
Bacillus subtilis. The Total Plate Count colony resulted that all films containing EOs only showed 0-1 bacteria colony
compared to BC films possed 1-5 colonies. All compounds of films were still available based on FTIR results. Physical
and mechanical characteristics of all films (tensile, elongation, solubility and WVTR) with respect to its structure and
physicochemical properties were performed. The SEM analysis showed the fine and smooth surface of films containing
EOs but BC film still revealed pores and roughness. Conclusion: The essential oils improved the characteristic of films
and proved the usage of films as carrier for antioxidant and antibacterial properties.

Keywords: biocellulose, antioxidant, antibacterial, essential oil, bioactivity

\section{INTRODUCTION}

Biocellulose or bacterial cellulose (BC) is an organic polymer that produced particularly by Acetobacter xylinum through oxidizing glucose to gluconic acid and organic acids simultaneously [1-2]. The BC displays unique properties including high tensile strength, high water absorption capacity, high crystallinity and an ultra-fine, higher degree of polymerization and higher crystallization index than plant cellulose and highly pure network fiber nanofibrillar structure. [1-3]. Nowadays, BC has been applied in multiple fields as it consists of biodegradable components and high water resistance performance such as antimicrobial wound dressing, blood vessel regeneration [4], redox flow battery, electrical conductivity [5-6], and food packaging to wrap the product[7-8]. Films have also been used as carriers for foods additives such as antioxidant or antimicrobial agent to improve original film, to extend the lifetime of food product[9] and to reduce the materials that contribute to environmental contamination as well [10]. One of sources of antioxidants and antimicrobial agents are essential oils (EOs) that have demonstrated their ability for eliminating microbial population and inhibiting the free radical in order to help food products with higher quality and safety [9,11]. In the present study, Cinnamomum cassia essential oil (Cc-EO) and Citrus maxima oil (Cm-EO) are antibacterial and antioxidant agent that incorporated with BC-based film.

The studies showed EOs inhibited the growth of bacteria Streptococcus pyogenes, Pseudomonas aeruginosa, Escherichia coli, Pseudomonas aeruginosa, and Staphylococcus aureus [11-12]. The phytochemical compound of C.cassia and C. maxima showed that polyphenol (tannin, flavonoids) and phenolic volatile oil are the major antioxidant compounds [13-15]. In this study, film incorporated with EOs are conducted as films for food packaging and characterized the physical mechanic properties of films. 
Even BC is an excellent choice for food packaging, there is no study BC-based film containing the antibacterial and antioxidant properties to prevent food contamination, yet. Therefore, the incorporation antimicrobial and antioxidant properties with BC is one of the promising technologies that effectively impregnates bioactive substances into the food packaging material and eliminates the pathogenic microorganisms affecting food products.

\section{MATERIALS AND METHODS}

Cinnamomum cassia essential oil (Cc-EO) and Citrus maxima oil (Cm-EO) were purchased from Lansida Group, Yogyakarta, Indonesia. Nata de coco gels were purchased from local industry in Cianjur, West Java Province, Indonesia. Gels were washed, boiled with water until the gels were stable on $\mathrm{pH} 7$. A total of $0.5 \mathrm{~kg}$ gel was blended with $200 \mathrm{~mL}$ water to obtain the slurry. An amount of $100 \mathrm{~mL}$ slurry was added with $1.0 \%$ carboxymethyl cellulose (CMC) and $200 \mu \mathrm{L}$ glycerol and mixed in a beaker glass under the magnetic stirring condition at $65^{\circ} \mathrm{C}$ for 45 minutes. After cooling, it was added with $1-3 \%$ EOs and $0.01 \%$ Tween 80 , then poured into the trays. The trays were held overnight at $45^{\circ} \mathrm{C}$ in oven blower, then cooled at room temperature before peeling the films off the trays and stored in plastic bags until used.

For Antioxidant assay, a total of $0.5 \mathrm{~g}$ of the film was extracted with $10 \mathrm{ml}$ methanol to obtain methanol extract. For the evaluation, $2.0 \mathrm{ml}$ of $0.1 \mathrm{mM}$ DPPH solution was added with $1.0 \mathrm{ml}$ of sample in a test tube, shaken and incubated in dark room for 30 minutes. Then, samples were read using a spectrophotometer at $517 \mathrm{~nm}$. The antioxidant activity was calculated as percentage inhibition of DPPH, using the following equation:

$\%$ inhibition $=($ Ao-As $) /$ Ao $\times 100 \%$

Ao is the absorbance of DPPH and As is the absorbance of the sample.

The antibacterial activity of films that incorporated with EOs against the bacteria growth (Escherichia coli, Pseudomonas aeruginosa, Salmonella thypii, Bacillus subtilis and Staphylococcus aureus) and the EOs were tested and determined by the disc diffusion assay. Film samples were cut into discs $6 \mathrm{~mm}$ and placed on plates containing Mueller-Hinton agar (MHA)(Himedia) which had been previously seeded with $100 \mu \mathrm{L}$ of an overnight broth bacteria culture. The commercial paper discs $\theta 6 \mathrm{~mm}$ containing EOs also were conducted as a positive control of the antibacterial test. The plates were incubated at $37^{\circ} \mathrm{C}$ for $24 \mathrm{~h}$ and the clear zone formed around the film discs and paper discs on the media were recorded.

The tensile and elongation of films were characterized by Orientec UCT-5T universal testing with $100 \mathrm{kgf}$ load cell according to ISO 527- 1993E standard method.

Fourier-transform infrared (FTIR) spectroscopy was conducted with Thermo Scientific Nicolet iS5 Spectrophotometer using the potassium bromide disk technique, in the range of 4000-500 cm-1 with an attenuated reflectance (ATR). Films were examined for surface characteristics using SEM JEOL JSM IT-300 JAPAN operating at 20kV. Film pieces were mounted on aluminium stubs using double-sided tape and then coated with a layer of gold (40-50 nm), allowed surface visualization

\section{RESULTS AND DISCUSSION}

The antioxidant activity of the essential oils (Cinnamomum cassia and Citrus maxima) and all films containing Cinnamomum cassia oil (F.Cc-EO) and Citrus maxima oil (F.Cm-EO) were showed and described in Figure (1). Based on Figure (1), the essential oil inhibited DPPH about $95.78 \%$ (Cc-EO) and $62.16 \%$ (Cm-EO) respectively. The films containing EOs (1-3\%) revealed percentage inhibition of DPPH about $91.78-42,16 \%$. The film containing $2 \%$ C. cassia oil (Cc-EO) performed the best antioxidant activity $(91.78 \%)$. All concentration of $\mathrm{Cm}$-EO (1 and 3\%) also still showed antioxidant activity. Meanwhile, only film incorporated with 3\% C.maxima showed antioxidant activity (72.71\%). The antioxidant activity of EOs decreased along incorporated with $\mathrm{BC}$ because of evaporated volatile compounds of EOs. One or more the EOs compounds in BC or films might evaporate when $\mathrm{BC}$ slurry was held overnight at $45^{\circ} \mathrm{C}$ in oven blower. BC films also stored in room temperature Figure (3-4). It indicated that the decreasing of antioxidant activity of films was due to the storage temperature. A study of volatile compounds from Croatian virgin olive oils showed that Virgin olive oils stored at low temperatures $\left(+4{ }^{\circ} \mathrm{C}\right.$ and $\left.-20{ }^{\circ} \mathrm{C}\right)$ maintained better quality parameters than oils stored at room temperature and time storage time [16-17]. The essential oil and all films containing EOs showed antibacterial activity whereas the diameter of inhibition of essential oil was larger than films diameters and described in Figure (2). 


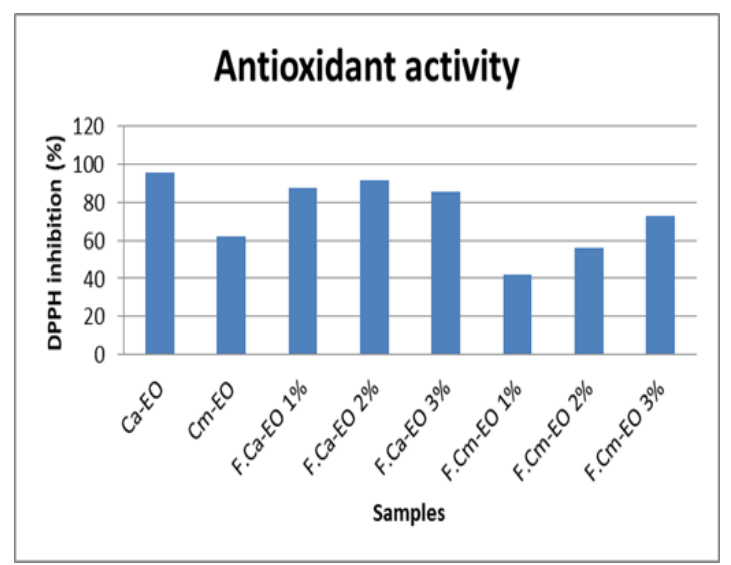

Fig.1. Antioxidant activity of EOs and films.

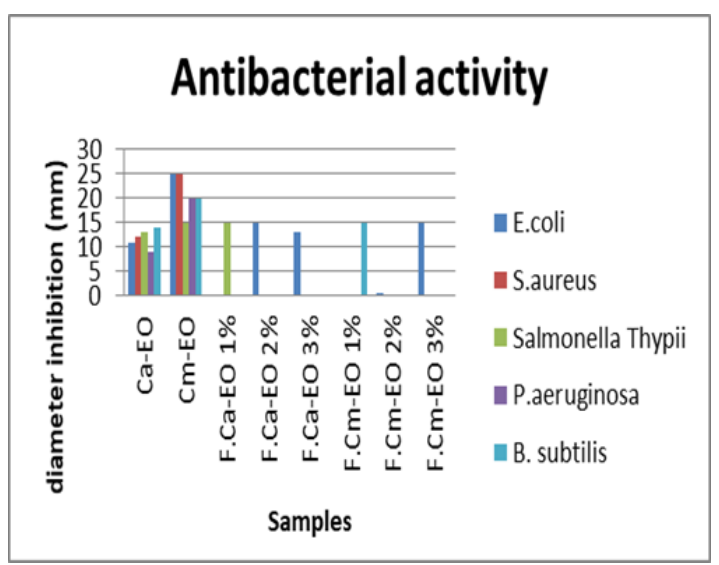

Fig.2. Antibacterial activity of EOs and films.

According to Figure (2), essential oil C.cassia and C. maxima revealed the antibacterial properties with diameter zones about 11$25 \mathrm{~mm}$ against pathogen bacteria growth (Escherichia coli, Staphylococcus aureus, Salmonella thypii, Pseudomonas aeruginosa and Bacillus subtilis). The scale of measurement of diameter of inhibition was as follows (disk diameter included): strong activity $>28 \mathrm{~mm}$, moderate activity: $16 \mathrm{~mm}<$ zone of inhibition $<28 \mathrm{~mm}$, mild activity: $12 \mathrm{~mm}<$ zone of inhibition < $16 \mathrm{~mm}$, and weak activity < $12 \mathrm{~mm}$ [18]. Oil C.cassia performed mild to weak antibacterial activity about 9-14 mm. Meanwhile, C.maxima possed mild to moderate activity with clear zones $15-25 \mathrm{~mm}$. The EOs could inhibit the bacteria cells, depending on the bioactive compounds of EOs and the sensitivity of bacterial cells to contact with EOs. The Cc-EO possed cinnamaldehyde compounds as major volatile that performed antibacterial substances for P. aeruginosa, E. coli, S. aureus, Salmonella para typhi B, Streptococcus oralis, Streptococcus anginosus, Streptococcus intermedius and Streptococcus sanguis, Enterobacter aerogenes and Micrococcus roseus [11,13,19]. The Cinnamomum plants also possed antibacterial substances which belonged to polyphenolic such as tannins, alkaloids, steroids and polyphenolic acids [18]. Meanwhile, the peels of Citrus spp including C.maxima produce aromatic and volatile compounds that perform an antimicrobial and antioxidant activity. The presence of phenols, tannins, saponin and D-limonene eliminated the growth of Bacillus licheniformis, B.subtilis, E.coli, S.thypii, P.aeruginoasa, and S.aureus in MHA medium [19-21].

The BC-based film containing EOs in Figure 3 (Cinnamomum oil) and Figure 4 (Citrus oil) still possed antibacterial properties. Figure (5) showed the antibacterial activity of films containing 1-3\% C.cassia oil were decreased compared with EO because of the effect of oven temperature when slurry in plates was dried. The volatile antimicrobe compounds were evaporated in the air. The clear zone of Cinnamomum oil against E.coli growth was $11 \mathrm{~mm}$, but addition 1-3\% oil into films showed inhibition zones 0 , 15 and $13 \mathrm{~mm}$ respectively. The C.maxima possed about $25 \mathrm{~mm}$ of diameter inhibition, and films Cm-EO (1-3\%) described clear inhibition 0, 0.7 and $15 \mathrm{~mm}$ respectively. Film Cc-EO only inhibited E.coli and S.thypii but film Cm-EO eliminated E.coli and B.subtilis.

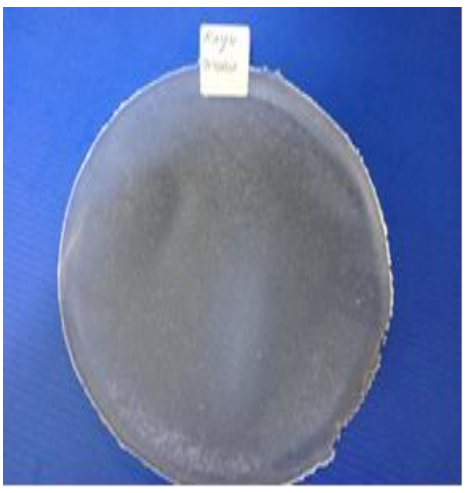

Fig.3. Film Cc-EO 2\%.

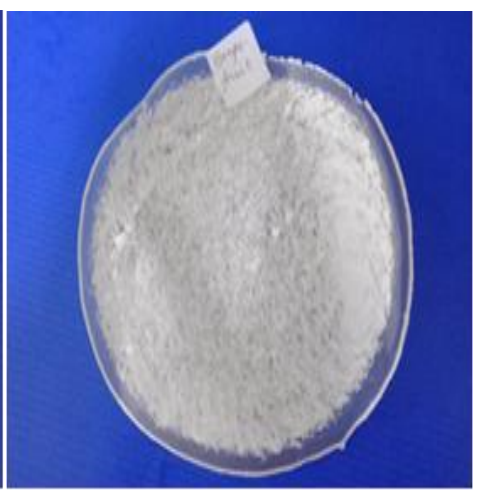

Fig.4. Film Cm-EO 2\%

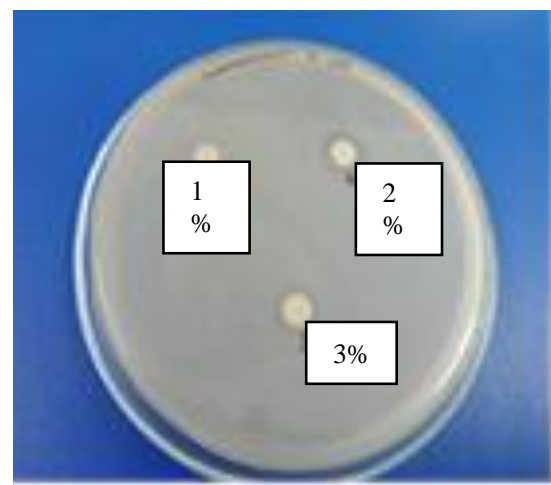

Fig.5. Film Cc-EO eliminated E.coli cells

The addition of essential oils in BC presented the change of the physical mechanic of films and was showed in Table 1.

Table 1. Characteristic properties of films containing essential oils.

\begin{tabular}{|l|l|l|l|}
\hline Physical-Mechanical Properties & Biocellulose film & Film Cc-EO 2\% & Film Cm-EO 2\% \\
\hline Tensile (Mpa) & 62,72 & 35.68 & 58,77 \\
Elongation (\%) & 20,00 & 26.25 & 27.50 \\
Solubility (\%) & 9,69 & 6,17 & 6,29 \\
WVTR ((g/m.s.kPa) & $2,35 \times 10^{-7}$ & $4,04 \times 10^{-7}$ & $2,19 \times 10^{-7}$ \\
& & & \\
\hline
\end{tabular}


Table 1. described that physical-mechanical properties of BC film were changed by the addition the essential oil. The EOs increased the elongation but decreased the films tensile. All films still obtained low-value solubility and water vapour transmission rate (WVTR) due to the hydrophobic of EOs which could interfere with the hydrophilic bonding in films. Addition oils containing phenolic compounds revealed a excellent barrier because the hydroxyl group has less affinity for water than for the carbonyl groups. A study about volatile essential oils (oregano, thyme, cinnamon, lemongrass, and clove) in edible films disrupted condense structure of film and produced a heterogeneous structure [9, 23-24].

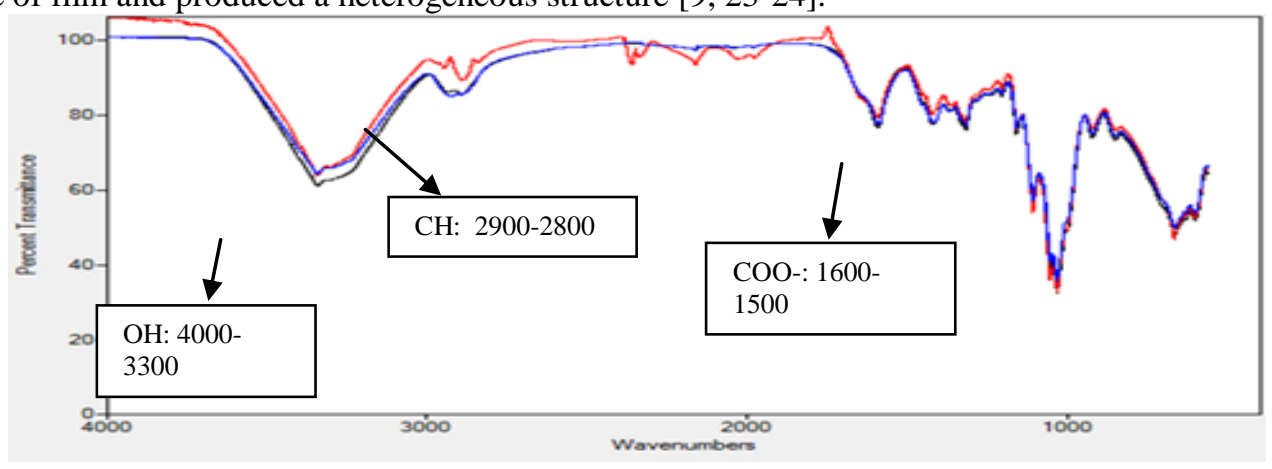

Fig.6. FTIR spectra of film BC ( $(\mathbf{c})$, film Cc-EO ( $)$ ) and film Cm-EO ( $)$

Based on FTIR spectra in Figure (6), all films showed $\mathrm{O}-\mathrm{H}$ group peak at $3300 \mathrm{~cm}-1$, performed an essential role in the physical properties of films. Peak at $2800-2900 \mathrm{~cm}-1$ indicated the presence C-H group. The COO- of CMC were obtained peak at $1500-1600 \mathrm{~cm}-1$. All spectra confirmed that the important bonds in cellulose polymer were present in the films even though the peaks and curves may change. Distinguish peaks should around $3300 \mathrm{~cm}-1$ to $3500 \mathrm{~cm}-1$ can be associated to the hydroxyl bonds of cellulose. The spectra region can be referred to as the intermolecular and intermolecular hydrogen bonds of cellulose [25]. SEM analysis of BC film Figure (7) showed the surface of the films possed roughness and many pores in the fibre because of the large molecule size of biocellulose. Composites (CMC and glycerol) were not dissolved with homogenous. The appearance of films containing essential oils Figure (8) showed the fibers were more solid, smooth and homogenous. There was no remarkable structural difference between film containing C.cassia with C.maxima oil so that EOs improved the flexibility and prevent cracks, pores and roughness. A similar study, SEM analysis showed the surface microstructural of the edible film from breadfruit starch incorporated with essential oil of attarasa leaves was more solid compared with film without incorporation of essential oils [9,26].
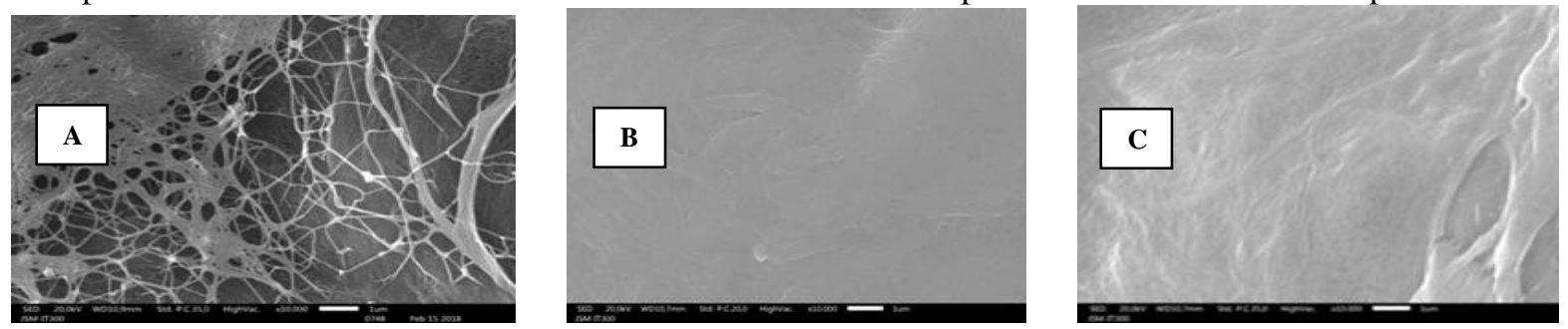

Fig.6. SEM micrographs of the surface of film BC (A), film Cc-EO (B) and film Cm-EO (C).

\section{CONCLUSION}

Addition of Cinnamomum cassia and Citrus maxima oils into bio cellulose-based films showed the effect on mechanical properties and the smooth surface of films compared to BC films. Films containing 2-3\% EOs performed antibacterial and antioxidant properties. The films can be used as food packaging in order to extend the lifetime of products and to eliminate pathogen microbes.

\section{ACKNOWLEDGEMENT}

This study was financially supported by Insinas Ristekdikti 2018 and Mandiri-LIPI project 2018.

\section{REFERENCES}

[1] S. Nur Binti Kamarudin, "Comparative Study of Bio-Cellulose from Acetobacter Xylinum 0416 and Commercial Hard Gelatine Capsule.” International Journal of Applied Engineering Research, vol.4, no.1, 2018 pp: 743-748

[2] L. Puji, E. Nitariani, S. Ani and S. Yadi, "Study on the Production of Bacterial Cellulose from Acetobacter xylinum Using Agro-Waste" Jordan Journal of Biological Sciences, vol. 7, no. 1, 2014 pp: 75-80

[3] K. Norasila and Norliza ABD Rahman, "Design and Production Control of Biocellulose from Acetobacter xylinum," Indian Journal of Science and Technology, vol. 9, no.21, 2016 pp:1-10

[4] M. Mona, B. Amin, Moghaddam, A. Susan and Raha A. Rahim, "Review: Production and Status of Bacterial Cellulose in Biomedical Engineering", Nanomaterials, vol.7, no. 275, 2017 pp: 1-26 
[5] T. Zhou, D. Chen, J. Jiu , T. Nge, T. Sugahara, S.Nagao, H. Koga, M. Nogi, K. Suganuma, X. Wang, X. Liu, P. Cheng, T. Wang and D. Xiong, "Electrically Conductive Bacterial Cellulose Composite Membranes Produced by The Incorporation of Graphite Nanoplatelets in Pristine Bacterial Cellulose Membranes”, eXPRESS Polymer Letters, vol. 7, no. 92013 pp: $756-$ 766

[6] V.A. Barbash, O.V. Yaschenko1, S.V. Alushkin, A.S. Kondratyuk, O.Y. Posudievsky and V.G. Koshechko, "The Effect of Mechanochemical Treatment of the Cellulose on Characteristics of Nanocellulose Films," Nanoscale Research Letters, vol.11, no. 4102016 pp: 1-8

[7] E. Faezah, Siti M. Tasirin and Norliza A. Rahman., "Overview of Bacterial Cellulose Production and Application", Agriculture and Agricultural Science Procedia, vol. 22014 pp:113 - 119

[8] L. Indrarti and Indriyati, "Incorporation of citrus Essential Oils Into Bacterial Cellulose-Based Edible Films and Assessment of Their Physical Properties," IOP Conf. Ser.: Earth Environ. Sci, vol.60 2016 pp:1-7

[9] D. Alireza, K. Ramin, H. Hedayat H, S. Saeedeh and G.Kiandokht, "Physical, Antioxidant and Antimicrobial Characteristics of Carboxymethyl Cellulose Edible Film Cooperated with Clove Essential Oil," Zahedan Journal of Research in Medical Sciences, vol.16, no.8 2014 pp: 34-42

[10] Y. Gaofeng, L. Hua, Y. Bingjie, C. Xiaoe and S. Haiyan, "Physical Properties, Antioxidant and Antimicrobial Activity of Chitosan Films Containing Carvacrol and Pomegranate Peel Extract," Molecules," vol.20 2015 pp: 11034-11045

[11] F.F. Diego, T.A.C. Theodora, A.G. Geovany, C.S.F. Nairley, D.R. Lucas, G.C. Mário and E.A. C. Francisco Jr, "Antibacterial and Antibiofilm Activities of Cinnamomum Sp. Essential Oil and Cinnamaldehyde: Antimicrobial Activities," The Scientific World Journal, vol. 12018 pp:1-9

[12] Pritam, D. N., Hemant, G., Anu, G., Niharika, S. and Monica, K. and Ramalingam, C., "Comparison of antimicrobial activity of Cinnamomum zeylanicum and Cinnamomum cassia on Food Spoilage Bacteria and Water Borne Bacteria," Der Pharmacia Lettre, vol.5, no. 12013 pp :53-59

[13] Y. Cheng-Hong, L. Rong-Xian and C. Li-Yeh, C, "Antioxidant Activity of Various Parts of Cinnamomum cassia Extracted with Different Extraction Methods," Molecules, vol. 172012 pp: 7294-7304

[14] M. Ervina, Y.E. Nawu and S.Y. Esar, "Comparison of In Vitro Antioxidant Activity of Infusion, Extract and Fractions of Indonesian Cinnamon (Cinnamomum burmannii) Bark," International Food Research Journal, vol. 23, no. 32016 pp: $1346-1350$

[15] G. Vadivukarasi and J. Agnes, "In Vitro Studies on Phytochemical Analysis and Antioxdant of Citrus maxima," Int.J. of Res.in Pharmacology and Pharmacotherapeutics, vol. 4, no.2 2015 pp: 245-251

[16] K. B.Brkic, O. Koprivnjakb, B. Sladonjaa and I. Belobrajic'a, I "Influence of Storage Temperature on Quality Parameters, Phenols and Volatile Compounds of Croatian Virgin Olive Oils," Grasas Aceites, vol. 65, no.3 2014 pp: 1-10

[17] I.P. Christina, V. George, G. Panagiotis, G. Demertzis and A. Konstantoula, "Effect of Storage Time, Storage Temperature and Packaging Material on the Composition of Major Volatile Compounds of White Wines from Ionian Islands (Greece)," IOSR Journal of Agriculture and Veterinary Science, vol.10, no.2 2018 pp: 33-42.

[18] M. Elgayyar, F.A. Draughon, D.A. Golden and J.R. Mount, "Antimicrobial Activity of Essential Oils from Plants against Selected Pathogenic and Saprophytic Microorganisms," Journal of Food Protection, vol. 64, no.7 2001 pp: 1019-1024

[19] O. A. F. Ilusanya1, O.A.Odunbaku, J.S. Ashidi and O.T. Adetoyinbo, "Antibacterial Activities of Extracts of Cinnamomum Cassia and Xylopia aethiopica on Clinical Pathogens," Journal of Biology, Agriculture and Healthcare vol. 7, no. 12 2017 pp: $1-5$

[20] S.A.B. Aimee, A.H. Wilma, A.P. Irene and O.Z. Teofila, "Phytochemical Composition, Antioxidant and Antibacterial Properties of Pummelo (Citrus maxima (Burm.)) Merr. Against Escherichia coli and Salmonella typhimurium," Food and Nutrition Sciences, vol.5 2014 pp: 749-758

[21] P. Vijaylakshmi and R. Radha, "An overview: Citrus maxima," The Journal of Phytopharmacology, vol.4, no.5 2015 pp: 263-267

[22] H.K Naeem, J.Q. Chin, P. Nabila, "Phytochemical Screening, Antimicrobial and Antioxidant Activity Determination of citrus maxima Peel," Pharmacy \& Pharmacology International Journal vol.6, no.4 2018 pp: 279-286

[23] L. Indrarti and Indriyati., "Incorporation of Citrus Essential Oils Into Bacterial Cellulose Based Edible Films and Assessment of Their physical properties," IOP Conf.Series: Earth and Environmental Sciences vol.60 2017 pp: 1-7

[24] D. Wen-Xian, J.A. Roberto, S.T.H. Sui and H.M. Tara, "Antimicrobial volatile essential oils in edible films for food safety," Science against microbial pathogens: communicating current research and technological advances, vol.1 $2011 \mathrm{pp}: 1124-$ 1135

[25] B.C. Adebayo-Tayo, M.O. Akintunde and Alao S.O, "Comparative Effect of Agrowastes on Bacterial Cellulose Production by Acinetobacter sp. BAN1 and Acetobacter pasteurianus PW1" Türk Tarım ve Doğa Bilimleri Dergisi, vol. 4, no.2 2017 pp: $145-154$

[26] F.Z. Cut, K. Jamaran, Marpongahtun and M. Erman, "Effect of Esensial Oil of Attarasa Leaves (Litsea cubeba Lour. Pers) On Physico-Mechanical and Microstructural Properties Of Breadfruit Starch-Alginate Edible Film," Malaysian Journal of Analytical Sciences, vol.17, no.3 2013 pp: 370 - 375 